\title{
Pengaruh Pengekangan CFRP Sebagai Eksternal Confinement Pada Kolom Persegi Untuk Meningkatkan Curvature Ductility
}

\author{
Karmila Achmad \\ Dosen Teknik Sipil \\ Politeknik Negeri Balikpapan \\ Jl. Soekarno Hatta Km. 08 \\ milabpp@yahoo.co.id
}

\begin{abstract}
This research uses test materials. They are two of square colomns by aims to know the influence of containing external CFRP to the increasing of curvature ductility. C-1 is original column which is used as control column and C-1c is reinforcement column 1 lay CFRP. Curvature ductility review is done on 3 spots for both test materials, each in plastic hinge, a half high of column effective and as high as column effective. From the research shows the increasing of curvature ductility $C-1 C$ to $C-1$ is $228.23 \%, 164,71 \%$ and $122,73 \%$ each for plastic hinge area, a half of high column and as high as effective column
\end{abstract}

Keywords : CFRP, curvature ductility, Eksternal confinemen, RC column

\begin{abstract}
Abstrak
Penelitian ini menggunakan benda uji berupa 2 buah kolom persegi dengan tujuan untuk mengetahui pengaruh pengekangan eksternal CFRP terhadap peningkatan curvature ductility. $C-1$ adalah kolom original yang digunakan sebagai kolom kontrol dan C-1C adalah kolom perkuatan 1 lapis CFRP. Peninjauan curvature ductility dilakukan di tiga titik untuk kedua benda uji, masing-masing pada daerah sendi plastis, setengah tinggi efektif kolom dan setinggi efektif kolom. Dari hasil penelitian menunjukaan terjadi peningkatan curvature ductility C-1C terhadap C-1 sebesar 228,23\%, 164,71\% dan 122,73\% masing-masing untuk daerah sendi plastis, setengah tinggi kolom dan setinggi kolom efektif.
\end{abstract}

Kata kunci : CFRP, curvature ductility, Eksternal confinement dan Kolom persegi

\section{Pendahuluan}

Pada umumnya setelah terjadinya gempa bumi dengan skala yang cukup besar dapat mengakibatkan kerusakan struktur dan non-struktur pada bangunan yang terbuat dari konstruksi beton bertulang maupun dari bahan konstruksi lainnya. Bentuk dan tingkat kerusakan yang terjadi mulai dari yang ringan sampai berat.

Kolom sebagai elemen struktur bangunan yang memiliki peranan penting memerlukan perhatian dalam hal ductility. Dengan adanya tuntutan fungsional dan operasional bangunan sehingga perlu dilakukan penanganan terhadap kerusakankerusakan yang terjadi akibat gempa bumi berupa perbaikan maupun perkuatan elemen struktur.

Untuk menangani hal ini maka metode yang dapat dilakukan berupa metode perkuatan eksternal konvensional seperti: memperpendek bentang dari struktur, memperbesar dimensi beton (concrete jacketing), menambah plat baja (Steel Plate Jacketing), melakukan eksternal prestressing dan metode perkuatan eksternal modern berupa pemanfaatan Carbon Fiber Reinforced Polymer (CFRP).

\section{Metoda Penelitian}

Metoda yang dipakai dalam penelitian ini berupa pengujian eksperimental dengan rincian sebagai berikut : 


\section{Benda Uji}

Ada dua tipe kolom beton bertulang yang digunakan yaitu kolom original (C-1) sebagai kolom kontrol dan kolom perkuatan CFRP sebanyak 1 lapis (C-1C) sebagai eksternal confinement. Dimensi penampang kolom $350 \times 350 \mathrm{~mm}$, tinggi kolom $2000 \mathrm{~mm}$ dengan tinggi efektif $1100 \mathrm{~mm}$. Spesimen menggunakan tulangan longitudinal 8D19 dan tulangan transversal Ø10-200.

Dalam penelitian ini akan menggunakan strain gauge tulangan baja FLA-6-11 dan strain gauge fiber BFLA-58. Untuk masing-masing spesimen, Strain gauge FLA-6-11 dipasang pada tulangan longitudinal sebanyak 4 buah, pada 2 lapis sengkang sebanyak 4 buah dan 2 buah strain gauge BFLA-5-8 dipasang pada CFRP.
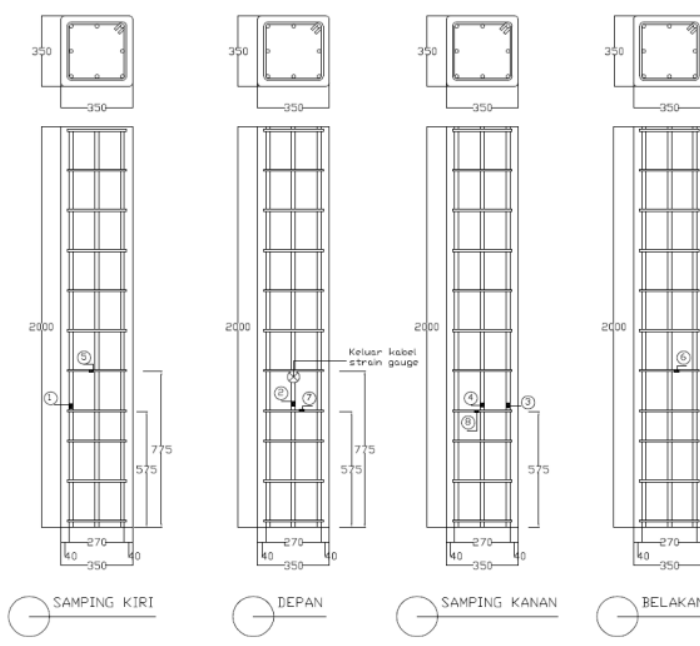

Gambar 1. Penempatan strain gauge tulangan

Aplikasi CFRP dengan metode wet lay-up dengan pemasangan full jacketing arah serat horisontal dan overlap $200 \mathrm{~mm}$. CFRP dipasang 1 lapis kecuali pada kepala kolom setinggi $775 \mathrm{~mm}$ dipasang 3 lapis dengan tujuan untuk menghindari kegagalan pada kepala kolom, seperti ditunjukan pada gambar 2. Aplikasi CFRP pada specimen perkuatan C-1C dilakukan setelah beton kering.

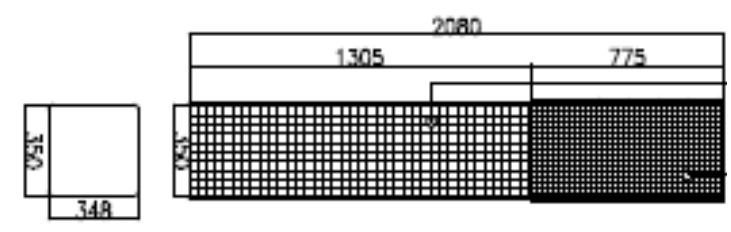

Gambar 2. Aplikasi CFRP

\section{Set-up Pengujian}

Pelaksanaan pengujian disesuaikan dengan peralatan yang tersedia di Laboratorium Puslitbang Teknologi Permukiman Departemen Permukiman dan Prasarana Wilayah, Bandung. Benda uji kolom yang diuji diposisikan berdiri tegak pada 2 buah rangka baja (loading frame) seperti dalam Gambar 3.

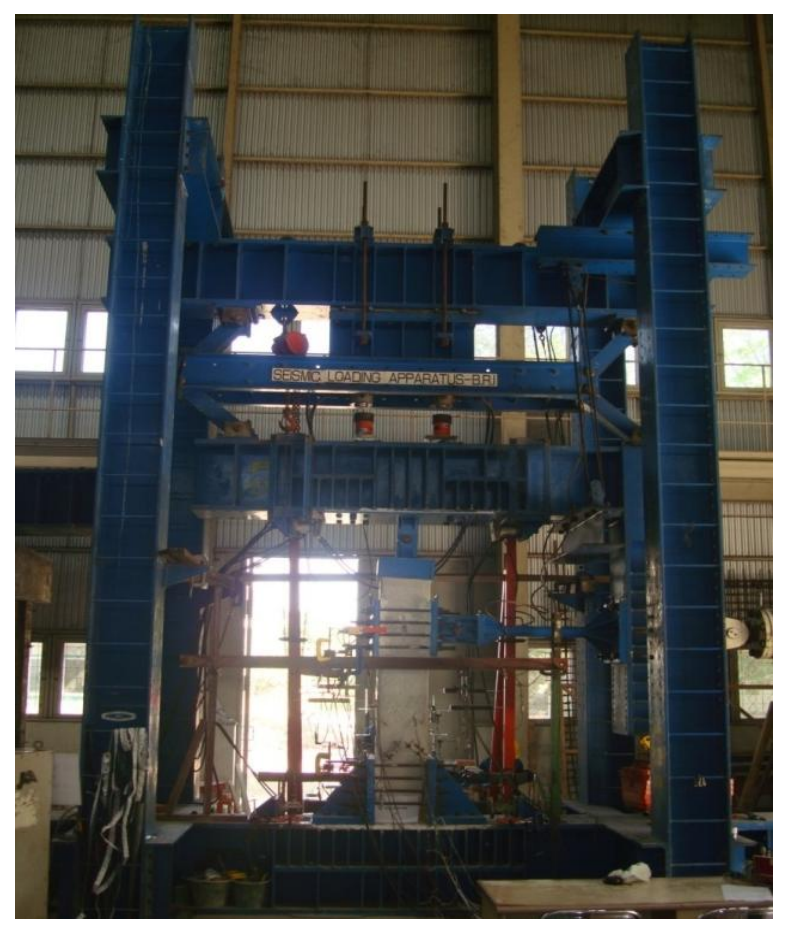

Gambar 3. Set-up pengujian kolom

Displacement beton diperoleh dari 18 Linear Variable Displacement Transducer (LVDT), masing-masing 8 buah diletakan didaerah sendi plastis, 2 dibagian tengah tinggi efektif kolom, 2 buah diatas, 6 buah dibawah sebagai kontrol alat bantu pelat baja bagian bawah. 


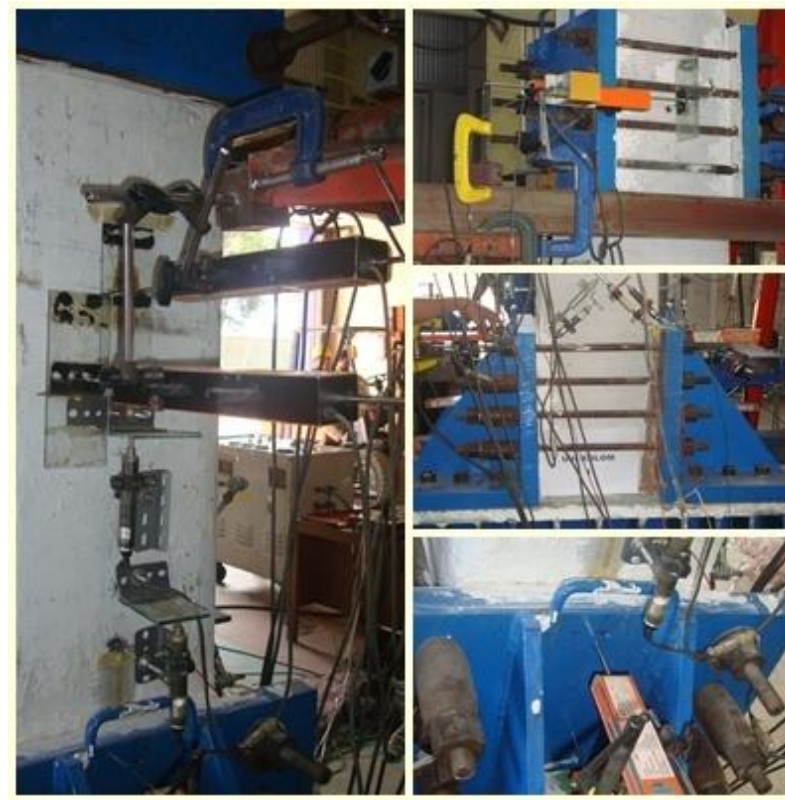

Gambar 4. Posisi LVDT

\section{Beban Rencana}

Besar beban aksial yang bekerja adalah konstan dan dilakukan variasi untuk beban siklik. Berdasarkan hasil analisa awal, dengan mengasumsikan kolom yang diuji adalah kolom pada lantai tengah gedung bertingkat maka beban aksial yang bekerja sebesar $30 \%$ dari kapasitas original column yaitu $748 \mathrm{kN}$. Sedangkan besarnya beban lateral yang bekerja pada masing-masing specimen adalah 181,57 $\mathrm{kN}$ untuk C-1 dan 225,95 kN untuk C-1C

\section{Hasil Penelitian}

\section{Pengujian Benda Uji C-1}

Kegagalan benda uji C-1 akibat spalling beton. $\mathrm{P}_{\max }$ tercapai pada drift $2,75 \%$ siklus pertama dengan nilai 278,9 $\mathrm{kN}$. Mulai spalling kolom terjadi pada saat beban mencapai $250,1 \mathrm{kN}$ dengan drift yang sama dengan saat tercapai $\mathrm{P}_{\max }$ yaitu $2,75 \%$ siklus ketiga dengan displacement sebesar 28,42 mm. Spalling ini terjadi pada sisi tekan kolom yang menyebabkan tulangan longitudinal terlihat dengan jelas.

Untuk benda uji C-1 kerusakan paling parah terjadi di kolom bagian bawah yaitu pada daerah sendi plastis mulai dari bawah sampai pada ketinggian sekitar $600 \mathrm{~mm}$ diukur dari atas dudukan pelat bawah.
Untuk benda uji C-1 kegagalan diakibatkan spalling beton dan hancurnya inti beton serta tekuk tulangan longitudinal. Selain didaerah sendi plastis, kerusakan juga terjadi pada kolom bagian atas. Dibagian atas kolom juga terjadi spalling meskipun tidak sebesar dan separah pada zona sendi plastis. Kegagalan benda uji C-1 ditampilkan pada gambar 5 .

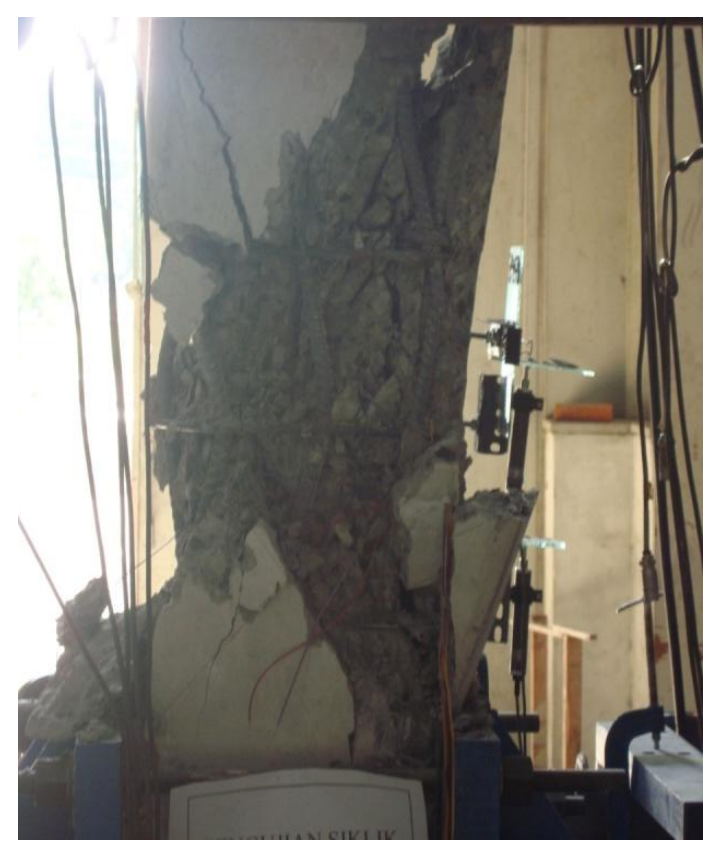

Gambar 5. Kegagalan benda uji C-1

\section{Pengujian Specimen C-1C}

Dari hasil pengamatan menunjukan bahwa kegagalan CFRP didahului dengan perubahan warna pada resin. Kegagalan dimulai dari beberapa serat di satu lokasi karena terjadi retak beton. Beban puncak terjadi pada step 800 rasio lateral drift $5 \%$ siklus pertama dengan nilai beban lateral 432,2 $\mathrm{kN}$ dan displacement yang terbaca dari LVDT adalah 54,4 mm. Sampai dengan akhir pola pembebanan yang diacu yaitu 5\% siklus ke tiga kondisi kolom secara keseluruhan masih baik dan kondisi ultimate benda uji belum tercapai. Sehingga rasio lateral drift ditingkatkan menjadi $5,5 \%, 6 \%, 7 \%$ dan berakhir di rasio lateral $d r i f t \quad 8,5 \%$ siklus ke tiga, 
Sampai akhir pengujian kolom secara keseluruhan tidak mengalami kehancuran. Pada daerah sendi plastis terjadi perubahan warna resin. Pada sisi samping kiri, kerusakan berupa putusnya fiber searah tulangan transversal sepanjang penampang kolom yang berlanjut kebagian depan benda uji sepanjang $3 \mathrm{~cm}$, Untuk bagian depan sendiri juga terjadi perubahan warna resin masing-masing sepanjang $1 \mathrm{~cm}$ dan $15 \mathrm{~cm}$ searah tulangan transversal. Sedangkan kegagalan kolom bagian samping kanan berupa perubahan warna resin yang sudah berupa luasan pada permukaan benda uji. Kerusakan ini setinggi $30 \mathrm{~cm}$ sepanjang penampang kolom. Untuk permukaan kolom daerah sendi plastis secara keseluruhan sudah tidak rata akibat rusaknya beton dibagian dalam. Kondisi akhir specimen $\mathrm{C}-1 \mathrm{C}$ ditampilkan pada gambar 6 .

Gambar 6. Kegagalan benda uji C-1C

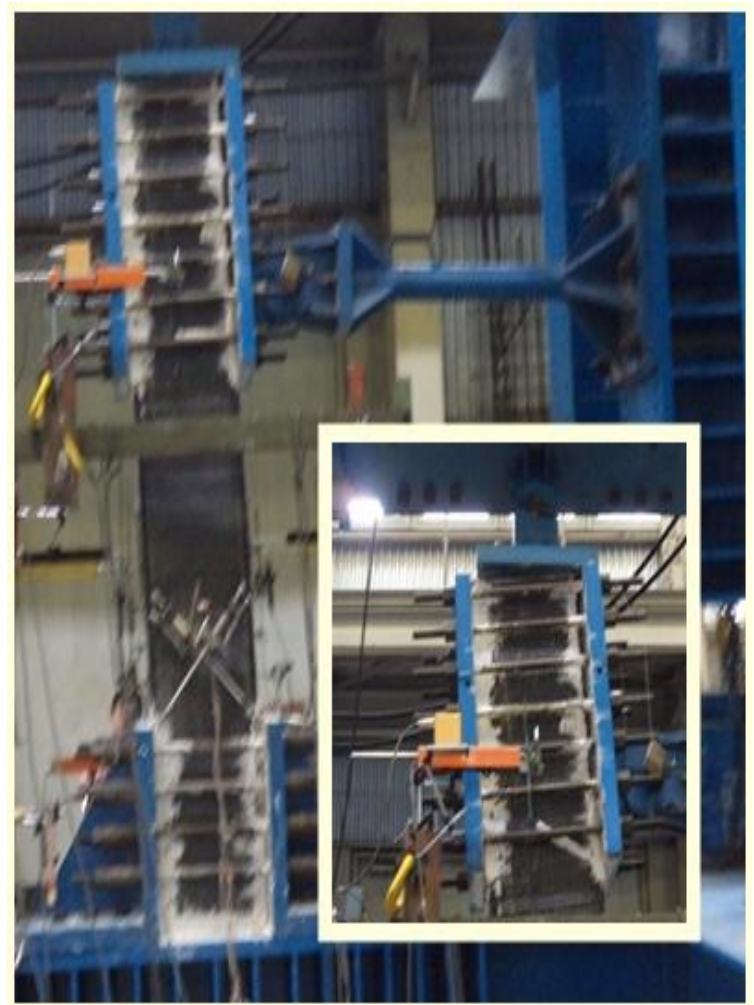

\section{Hubungan Momen-Curvature}

Dalam penelitian ini akan di ambil curvature ductility pada 3 posisi yaitu di daerah sendi plastis, di tengah tinggi kolom dan setinggi efektif kolom yaitu pada displacement maksimum.

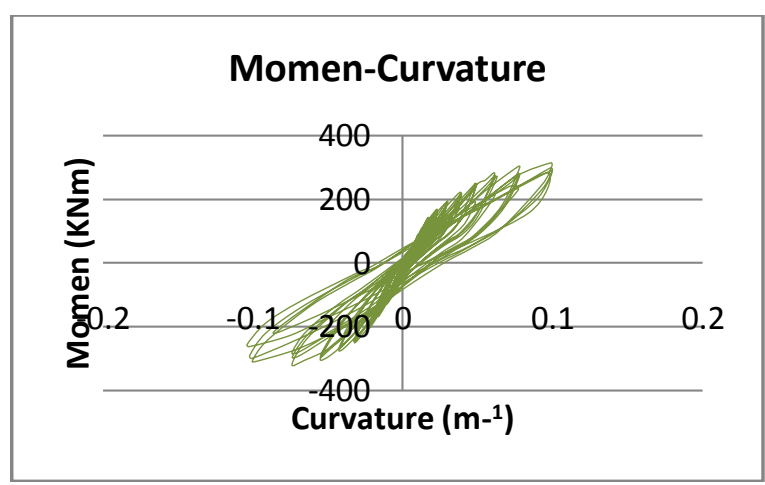

(a) Daerah sendi plastis

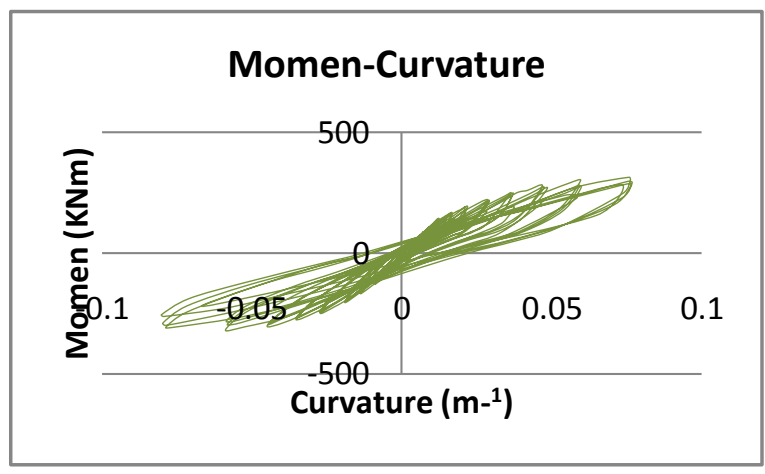

(b) Setengah tinggi kolom efektif

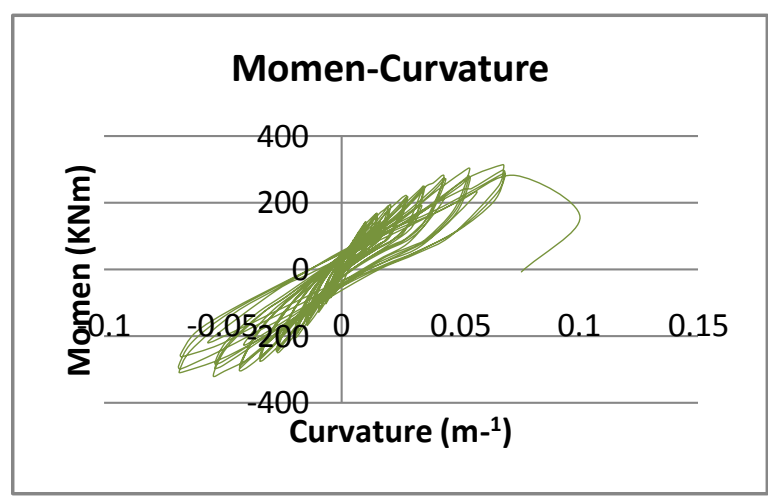

(c) Setinggi efektif kolom

Gambar 7. Grafik momen-curvature benda uji C-1 


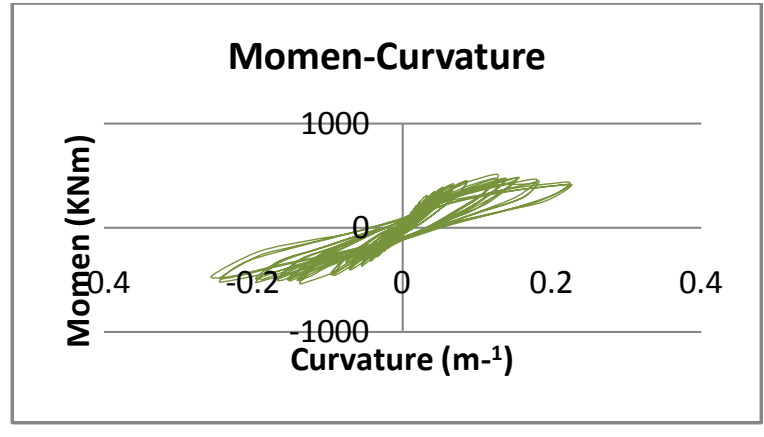

(a) Zona sendi plastis

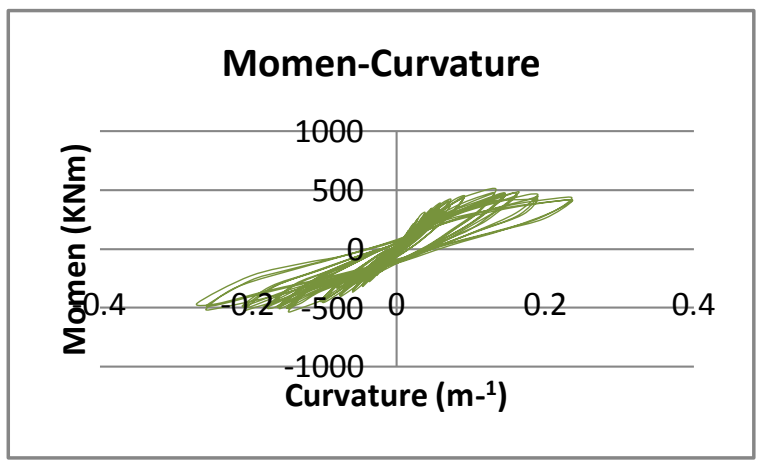

(b) Setengah tinggi kolom

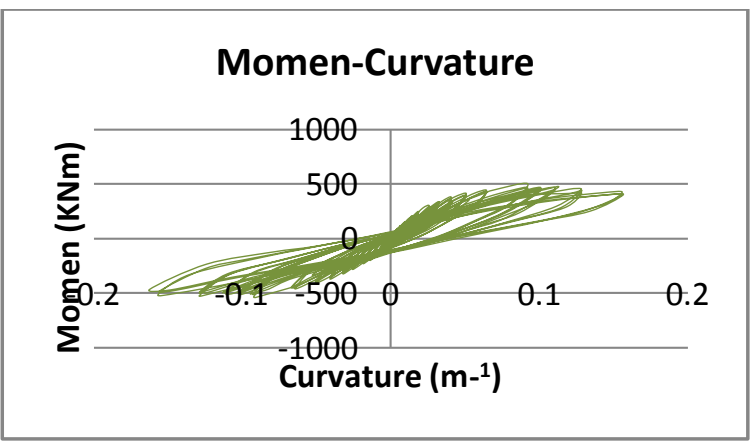

(c) Setinggi kolom efektif

Gambar 8. Grafik momen-curvature benda uji C$1 \mathrm{C}$

Dari grafik momen-curvature terlihat bahwa terjadi peningkatan momen maksimum untuk kolom $\mathrm{C}-1 \mathrm{C}$ dibandingkan dengan $\mathrm{C}-1$. Besarnya $\mathrm{M}_{\max }$ untuk $\mathrm{C}-1$ adalah $328,04 \mathrm{kNm}$ dan $\mathrm{C}-1 \mathrm{C}$ adalah 509,63 kNm. Peningkatan $\mathrm{M}_{\max } \mathrm{C}-1 \mathrm{C}$ terhadap C-1 sebesar 55,36\%.

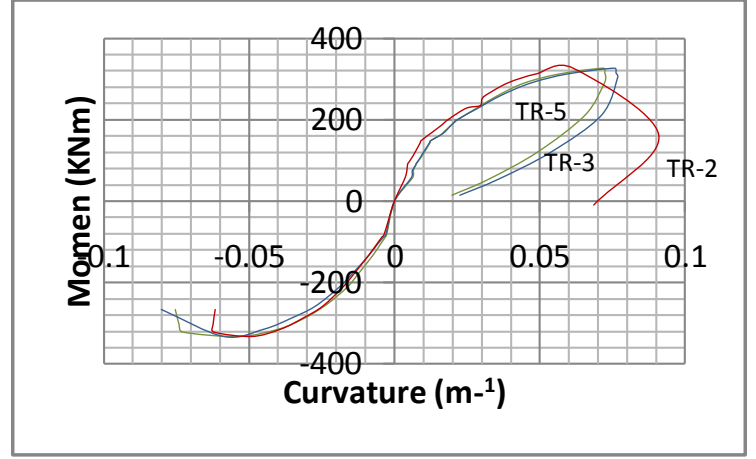

Gambar 9. Skeleton momen-curvature benda uji C-

1

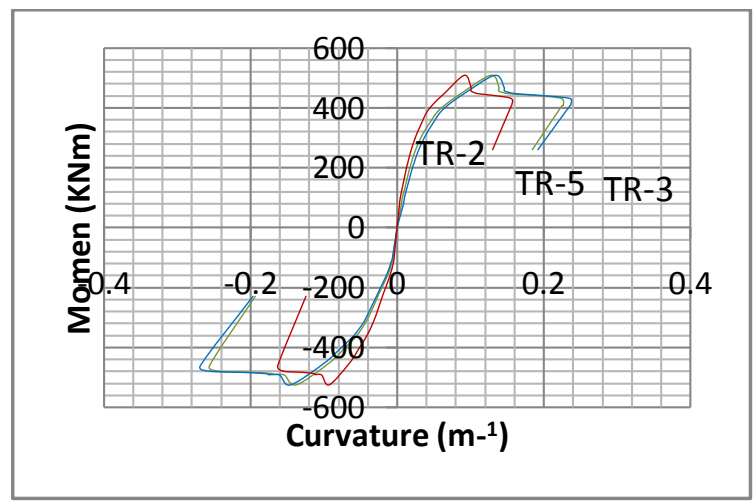

Gambar 10. Skeleton momen-curvature benda uji C-1C

Nilai curvature ductility C-1 untuk daerah sendi plastis, setengah tinggi kolom dan setinggi efektif kolom berturut-turut adalah 4,22; 4,50 dan 5,61. Curvature ductility kolom C-1C secara keseluruhan jauh diatas C-1 yaitu 13,84; 11,91 dan 12,51, masing-masing untuk zona sendi plastis, setengah tinggi kolom dan setinggi efektif kolom. Sehi ngga besarnya peningkatan curvature ductility C-1C terhadap C-1 adalah 228,27\%, $164,71 \%$ dan $122,74 \%$ untuk zona sendi plastis, setengah tinggi kolom dan setinggi efektif kolom.

\section{Kesimpulan}

Berdasarkan hasil penelitian pengaruh pengekangan eksternal CFRP sebagai eksternal confinement pada kolom persegi untuk meningkatkan curvature ductility seperti yang telah diuraikan maka dapat diambil kesimpulan sebagai berikut : 
a. Dari grafik momen-curvature diperoleh nilai curvature ductility untuk zona sendi plastis, setengah tinggi kolom dan setinggi efektif kolom masing-masing untuk C-1 adalah 4,22; 4,50 dan 5,61, C-1C sebesar 13,84; 11,91 dan 12,51.

b. Prosentase peningkatan $\mu_{\varphi} \quad \mathrm{C}-1 \mathrm{C}$ terhadap C-1 adalah 228,23\%, 164,71\% dan $122,73 \%$ masing-masing untuk zona sendi plastis, setengah tinggi kolom dan setinggi efektif kolom.

\section{Saran}

Diperlukan adanya penelitian lebih lanjut mengenai pengujian ekternal confinement dengan material CFRP dengan jumlah lapisan yang lebih bervariasi sehingga akan didapatkan perbandingan curvature ductility yang lebih akurat.

\section{Ucapan Terima Kasih}

Penulis mengucapkan terima kasih kepada FYFE Co. LLC Singapore dengan perwakilan di Indonesia adalah PT. Master Solusi Indonesia (MSI) atas bantuan dan kerjasamanya dalam menyediakan material CFRP $\quad\left(\right.$ Tyfo ${ }^{\circledR}$ Fibrwrap ${ }^{\circledR}$ Composite Systems) dan applicator-nya.

\section{Daftar Pustaka}

ACI 440.2R-02. "Guide for the Design and Construction of Externally Bonded FRP Systems for Strengthening Concrete Structures". ACI Committee 440, 2002

ACI 374.1-05. "Acceptance Criteria for Moment Frames Based on Structural Testing and Commentary". ACI Committee 374, 2005

Al-Sulayfani, B and Al-Taee, H. "Modeling of Stress-Strain Relationship for Fibrous Concrete Under Cyclic Loads" Eng.Tech.Vol.26, No1, 2008, pp. 45-53

Bae, S and Bayrak, O. "Seismic Performance of Full-Scale Reinforced Concrete Columns" ACI Structural Journal" March-April, 2008, pp. 123-133

Balaguru, P, Nanni, A and Giancaspro, J. "FRP Composites for Reinforced and
Prestressed Concrete Structures" Taylor \& Francis Group, New York, 2009

Bank, Lawrence. "Structural Design with FRP Materials" John Wiley \& Sons, INC, Canada, 2006

Benzaid, R, Chikh NE and Mesbah H. "Behaviour Of Square Concrete Column Confined With GFRP Composite Warp", Journal Of Civil Engineering And Management, 2008

Cole, C. and Belarbi, A. "Confinement Characteristics of Rectangular FRP-Jacketed $R C$ Columns", Proceedings of the Fifth International Symposium on Fiber Reinforced Polymer for Reinforced Concrete Structures (FRPRCS-5), Cambridge, UK, July 16-18, 2001, pp. 823-832.

Dhakal, RP and Maekawa, K. "Post-Peak Cyclic behavior and Ductility of reinforced Concrete Columns"

Faella, A, Napoli, A and Realfonzo, R. "Cyclic Behaviour of Concrete Columns Confined with FRP Systems" Fourth International Conference on FRP Composites in Civil Engineering (CICE2008), 22-24July 2008, Zurich, Switzerland, pp. 1-6

Gangarao, H, Taly, $\mathrm{N}$ and Gangarao, $\mathrm{H}$. "Reinforced Concrete Design with FRP Composites" CRC Press, Prancis, 2007

Harajli, $\mathrm{M}$ and Dagher, F. "Seismic Strengthening of Bond-Critical Regions in Rectangular Reinforced Concrete Columns Using Fiber-Reinforced Polymer Wraps" ACI Structural Journal, January-February 2008, pp.68-77

Kumar, ES, Murugesan, A and Thirugnanam, G.S. "Experimental Study on Behavior of Retrofitted with FRP Wrapped RC BeamColumn Exterior Joints Subjected to Cyclic Loading" International Journal of Civil and Structural Engineering, Vol. 1, No.1, 2010, pp.64-79

Lee, Chung-Sheng, Hegemier, GA and Philippi DJ. "Analitical Model for Fiber Reinforced Polymer Jacketed Square Concrete Columns in Axial Compression" ACI Structural Journal, 2010 pp.208-217 
Nawy, Edward. "Beton Bertulang Suatu Pendekatan Dasar" PT. Refika Aditama, Bandung, 2008

Panitia Teknik Standardisasi Bidang Konstruksi dan Bangunan. "Tata Cara Perhitungan Struktur Beton Untuk Bangunan Gedung (SNI 03-2847-2002)”. Badan Standardisasi Nasional. Bandung, 2002

Park, R and Paulay,T."Reinforced Concrete Structures" John Wiley and Sons, Canada, 1975

Rousakis, T and Tepfers, R. "Behavior of Concrete Confined by High E-Modulus Carbon FRP Sheets, Subjected to Monotonic and Cyclic Axial Compressive Load"

Saadatmanesh, H, Ehsani, MR and Li, MW. "Strength and Ductility of Concrete Columns Externally Reinforced with Fiber Composite Straps" ACI Structural Journal, 1994

Sheikh, SA and Liu, J. "Enhancing Seismic resistance of Concrete Columns with FRP" "
Proceedings fib Symposium PRAGUE, 8-10 June 2010

Tavio, Purwono, $\mathrm{R}$ dan Rosyidah, A. "Peningkatan Daya Dukung dan Daktilitas Balok Beton Bertulang Dengan Menggunakan Perkuatan CFRP (Carbon Fiber Reinforced Polymer" Dinamika Teknik Sipil, 2009

Teng, J. G, Huang, Y. L, Lam, L and Ye L. P. "Theoretical Model for Fiber-Reinforced Polymer-Confined Concrete", Journal of Composites Construction ASCE, March-April 2007, pp.201-210

Tim Revisi Peta Gempa Indonesia. "Ringkasan Hasil Studi Tim Revisi Peta Gempa Indonesia 2010” Bandung, 2010

Watanabe, K, Niwa, J, Yokota, $\mathrm{H}$ and Iwanami, M. "Stress-Strain Relationship for the Localized Compressive Failure Zone of Concrete under Cyclic Loading 